\title{
Fibrinogen Equivalent Unit
}

National Cancer Institute

\section{Source}

National Cancer Institute. Fibrinogen Equivalent Unit. NCI Thesaurus. Code C96649.

A unit of measure for the concentration of fibrin deg radation products in a sample, calculated based upon the mass of fibrinogen contained within that sample. 